\title{
Cortical projection of the inferior choroidal point as a reliable landmark to place the corticectomy and reach the temporal horn through a middle temporal gyrus approach
}

Projeção cortical do ponto coroideo inferior como uma referência anatômica confiável para a realização da corticectomia e abordagem do corno temporal através do giro temporal médio.

Thomas Frigeri ${ }^{1,2}$, Albert Rhoton ${ }^{1}$, Eliseu Paglioli², Ney Azambuja

\begin{abstract}
Objective: To establish preoperatively the localization of the cortical projection of the inferior choroidal point (ICP) and use it as a reliable landmark when approaching the temporal horn through a middle temporal gyrus access. To review relevant anatomical features regarding selective amigdalohippocampectomy (AH) for treatment of mesial temporal lobe epilepsy (MTLE). Method: The cortical projection of the inferior choroidal point was used in more than 300 surgeries by one authors as a reliable landmark to reach the temporal horn. In the laboratory, forty cerebral hemispheres were examined. Conclusion: The cortical projection of the ICP is a reliable landmark for reaching the temporal horn.
\end{abstract}

Keywords: amygdalohippocampectomy, microsurgical anatomy, inferior choroidal point, temporal lobe, temporal horn.

RESUMO

Objetivo: Estabelecer a projeção cortical do ponto coiroideo inferior e usá-la como referência para realizar a corticectomia e a abordagem do corno temporal do ventrículo lateral em cirurgias para o tratamento da epilepsia temporal mesial. Método: A projeção cortical do ponto coroideo inferior foi utilizada por um dos autores seniors em mais de 300 casos de epilepsia temporal mesial para atingir o corno temporal do ventrículo lateral. Conclusão: A projeção cortical do ponto coroideo inferior foi útil e confiável na abordagem do corno temporal do ventrículo lateral e ela está geralmente localizada na margem inferior do giro temporal médio, em média, a 4,52 cm posterior ao polo temporal.

Palavras-chave: amygdalohippocampectomia, anatomia microcirúrgica, ponto coroideo inferior, lobo temporal, corno temporal.

Epilepsy affects nearly $1 \%$ of the world's population ${ }^{1,2}$. One third of the adults with this condition are resistant to medical treatment and in this group, temporal lobe epilepsy due to mesial temporal sclerosis, represents the largest single etiology.

The surgical treatment for mesial temporal lobe epilepsy due to mesial temporal sclerosis has provided excellent seizure control $^{3,4,5,6,7,8,9,10,11,12,13}$. According to Yasargil et. al, patients with temporal lobe epilepsy (MTLE) presenting with localized abnormalities on investigative studies (EEG, MRI, PET), should not be subjected to lengthy experimental drug therapies, but be offered selective amygdalohyppocampectomy, a pure lesionectomy, while avoiding injury to unaffected temporal lobe ${ }^{14}$.

Although different techniques have been described for this procedure, selective amigdalohippocampectomy $(\mathrm{AH})$ has been widely accepted due to its excellent results and sparing of normal brain tissue with low post-operative morbidity.

In this article, after a short review of some of the important anatomical aspects regarding selective $\mathrm{AH}$, a simple and helpful method to locate and safely reach the temporal horn of the lateral ventricle, using preoperative measurements, is detailed. 


\section{SURGICAL ANATOMY}

At the lateral surface the superior limit of the temporal lobe is the sylvian fissure, the posterior limit is a line connecting the parieto occipital sulcus and the pre occipital notch. The lateral surface is divided in three gyri (superior, middle and inferior) separated by two sulci (superior and inferior temporal), both sulci and gyri are oriented parallel to the sylvian fissure ${ }^{15}$. The border between the middle and inferior temporal gyri are often not well defined because the inferior temporal sulcus is frequently interrupted by gyral bridges. In the basal surface there are three important sulci to be known. The rhinal, occipito temporal and the collateral sulcus. The occipito temporal sulcus is located between the inferior temporal gyrus and the fusiform gyrus and the collateral sulcus between the fusiform and the parahippocampal gyrus. Both have an anterior posterior orientation. The collateral sulcus bulges into the ventricular cavity forming the collateral eminence lateral to the body of hippocampus, being a helpful anatomical landmark for microsurgical guidance. The collateral eminence is the lateral limit of selective $\mathrm{AH}$. The rhinal sulcus is the anterior continuation of the collateral sulcus, bulging into the ventricular cavity lateral to the head of the hippocampus.

The inferior choroidal point (ICP) is located immediately behind the head of the hippocampus at the lower end of the choroidal fissure, it is the site of entrance of the anterior choroidal artery and the site of exit of the inferior ventricular vein into the temporal horn. Posterior to it, the medial temporal surface is formed by three longitudinal strips of neural tissue, one located above the other ${ }^{16}$. The inferior strip is the parahippocampal gyrus, followed by the dentate gyrus and superiorly by the fimbria fornix.

The parahippocampal gyrus extends forward to form the inferior half of the posterior part of the uncus, the head of hippocampus forms the superior half while the amygdala forms the anterior half. The uncus is divided in three segments: anterior and posterior which blend together in a medially projecting apex. The amygdala blends superomedially, along the lateral edge of the optic tract, into the globus pallidus without a clear demarcation. The apex of the uncus extends medially above the tentorial incisura and is positioned lateral to the oculo motor nerve and medial to the uncal recess which extends medially between the amygdala and the head of the hippocampus.

The temporal horn is covered superolaterally by a thin layer of callosal tapetal fibers which course outside the ependymal walls and separates the optic radiations from the temporal horn.

The optic radiations arise from the lateral geniculate body in three bundles. The anterior bundle curves anterolaterally above the temporal horn (Meyer's loop) usually reaching beyond the anterior limit of the temporal horn and then loops backward along the lateral wall. This bundle is transected horizontally during trans middle temporal gyrus approaches

\section{IMPORTANCE OF THE ICP}

The ICP is an important landmark in mesial temporal surgery. It is located at the posterior edge of the uncus at the junction of the crural and ambient cistern and at the lower end of the choroidal fissure along which the choroidal plexus is attached. It is the site of entrance of the anterior choroidal artery into the temporal horn (where the plexal segment of the artery begins), and also the point of exit of the superior ventricular vein. Also the transition between the crural and the ambien cisterns is located at this level.

The ICP is located at about the middle length of the anteroposterior resection for selective $\mathrm{AH}$. The posterior edge of the resection usually extends approximately $1 \mathrm{~cm}$ behind the inferior choroidal point, which corresponds to the approximate level of the lateral geniculate body and lateral mesencephalic sulcus.

\section{METHOD}

Forty formalin fixed hemispheres were examined, using $\mathrm{x} 3$ to $\mathrm{x} 40$ magnification.

A lumbar puncuture needle introduced at the ICP, passed from medial to lateral, in a straight line following an axial plane, though the cortical surface. The ICP was defined as the the lower end of the choroidal fissure.

The distance from the ICP to its cortical projection was measured. The next measurements were from the cortical ICP to the temporal pole, lower edge of the sylvian fissure and infero lateral margin of the temporal lobe.

These same measurements were made in preoperative MRIs of 300 patients submitted to selective AH through middle temporal gyrus approach. The cortical ICP was used to establish the center of the corticectomy. A $2.5 \mathrm{~cm}$ cortical incision was made centered over the cortical ICP in order to reach the ventricle with a satisfactory exposition of the mesial temporal structures to be resected.

All the surgeries were performed by one of the authors at the Hospital Sao Lucas, Epilepsy Surgery Program at the Pontiff Catholic University of Rio Grande do Sul, Porto Alegre, Brazil. Cadaveric dissections were performed at the Microneuroanatomy laboratory of the University of Florida.

\section{RESULTS}

In the laboratory studies, the cortical ICP was located in average 2,26 cm (range, 1,97 - 2,61) from the sylvian fissure, 
$1,97 \mathrm{~cm}$ (range, 1,90 - 2,31) from the infero lateral margin of the temporal lobe and 4,52 cm (range, 4,01 - 4,88) from the temporal pole. The distance from the ICP to the cortical surface averaged of 4,33 $\mathrm{cm}$ (range, 3,93 - 4,57). It was found to be most likely located over the middle temporal gyrus, slightly above the inferior temporal sulcus (Table).

Immediately before the surgery, the authors establish the cortical projection of the ICP on the patient's MRI. The previously described measurements are then performed establishing its distance to the sylvian fissure, temporal pole and lower margin of the lateral surface of the temporal lobe.

After performing a temporal craniotomy and opening the dura, the surgeon applies the preoperative measurements and establishes the cortical projection of the inferior choroidal point over the temporal surface. An horizontally oriented $2.5 \mathrm{~cm}$ corticectomy centered on this point is performed. Dissection then is directed medially, within the white matter, towards the temporal horn.

These measurements were helpful in defining the site for the corticectomy having the inferior choroidal point on its center. It provided a good surgical exposure of the mesial temporal structures with satisfactory centralized visualization of the surgical field, requiring small brain retraction and displacement.

Even though it is necessary to incise through the anterior bundle of the optic radiations, no patient had any postoperative visual complaints. The incision was longitudinal to the fibers, therefore causing less damage than a perpendicular incision. The visual deficits were either absent or subclinical. The next step would be to perform an accurate visual field test in these patients.

Regarding seizure control, a long term follow up confirms the excellent results of this technique ${ }^{3,6}$.

\section{DISCUSSION}

Reliably accessing the temporal horn is an important step in mesial temporal lobe surgery. Errors in finding the temporal horn, can lead to unnecessary resection of healthy tissue, damage to eloquent structures and misunderstanding of the normal brain anatomy.

Table. Measurements from the cortical projection of the ICP to anatomical references on the lateral surface of the cerebrum

\begin{tabular}{lccc} 
Measurements & Average & Range $(\mathrm{cm})$ & SD \\
\hline ICPP - TP & 4.52 & $4.01-4.88$ & 0.249123 \\
ICPP - SF & 2.26 & $1.97-2.61$ & 0.189306 \\
ICPP - LTM & 1.97 & $1.90-2.31$ & 0.124875 \\
ICP - TC & 4.33 & $3.93-4.57$ & 0.272012 \\
\hline
\end{tabular}

ICP: inferior choroidal point; TP: temporal pole; SF: sylvian fissure; LTM: lower temporal margin; TC: temporal cortex; SD: standard deviation.
Different techniques have been described with the objective of making the access to the temporal horn simple $\mathrm{e}^{10,12,13,14,15,16,17,18,19,20}$.

Wen et al, described a technique where the surgeon must dissect within the white matter until one reaches the gray matter of the collateral sulcus and then turns the dissection upward.

Olivier et al, use the central or precentral sulcus as the posterior limit of the corticectomy.

Wheatley et al, using navigation system, define a line extending from the middle temporal gyrus to the lateral mesencephalic sulcus and perform the corticectomy anterior to this line.

Spencer et al, also use navigation system to define the position of the temporal horn and perform the corticectomy over the middle temporal gyrus in an area free of vessels.

When using this simple but effective technique, the surgeon must be careful in positioning the patient's head. The ideal position is achieved applying more rotation to the contralateral side and more extension of the neck than in a regular pterional craniotomy. By performing these maneuvers, the lateral temporal lobe surface will be positioned almost parallel to the floor and the mesial temporal region will present itself more lateral, facilitating the entry into the temporal horn ${ }^{21}$.

It is important to check if the lateral surface of the temporal lobe is parallel to the floor so that the dissection trough the white matter is perpendicular to the surface. If possible, we usually extend the neck a few degrees more in order to have the lateral surface of the temporal horn as the highest point at the surgical field. If this extra extension is possible, then the surgeon must remember to slightly incline the dissection path through the white matter caudally.

Dissection pathway after passing through the gray matter of the middle temporal gyrus must be conducted straight medially within the white matter of the temporal lobe. Usually no more than $3 \mathrm{~cm}$ of resection is necessary to reach the ventricle ${ }^{22}$.

If using this technique, one does not enter the temporal horn upon reaching expected depth, it is likely that the dissection was directed too far superiorly or inferiorly. Using the cortical projection of the inferior choroidal point makes it unlikely that the opening happens too far anterior. The temporal horn tip is located approximately $3 \mathrm{~cm}$ behind the temporal pole and our cortical incision is centered at the ICP which is located $1 \mathrm{~cm}$ behind the tip in average.

As described in the surgical anatomy, there is no clear demarcation between the temporal lobe and the basal ganglia. If the dissection was carried too superiorly there is a great risk of damaging the optic tract, temporal stem, the lentiform nucleus and the internal capsule. In order to avoid this mistake one must be sure that the angle of the dissection is along the junction of the axial and coronal planes passing through the cortical ICP. 
An incision placed too low, or a caudal deviation of the dissection will probably reach the gray matter overlying the temporo basal sulci (collateral or rhinal). To correct this deviation, the surgeon must carry the dissection upward, back within the white matter in order to reach and enter the ventricle.

The goal of using this landmark is to avoid misleading when reaching the temporal horn in epilepsy surgery. Thus, providing a clean surgical field, preservation of the normal brain anatomy and allowing the resection of what is strictly necessary to reach the ventricle, a small amount of normal tissue.

Neuronavigation devices can be very helpful in locating the temporal horn when available. However it is associated with a registration error great enough to miss the ventricle.

The technique described in this article is useful to reach the temporal horn when there is no displacement of the latter or adjacent structures, as in hippocampal atrophy for example.

Despite all the technology available, the precise three dimensional knowledge of the temporal lobe anatomy is the best resource to achieve accuracy in mesial temporal resections.

This study identified the cortical projection of the inferior choroidal point as an excellent guide to reach the temporal horn in a safe and non traumatic way ${ }^{3,6,20}$. It allows the surgeon to limit the corticectomy while maximizing exposure of the amygdala and hippocampus.

These preoperative measurements should be done individually, taking into consideration the anatomic variations of each patient, in order to define the cortical ICP and the site of the corticectomy.

\section{References}

1. Shukla G, Prasad AN. Natural history of temporal lobe epilepsy: antecedents and progression. Epilepsy Res Treat. 2012;2012:195073. http://dx.doi.org/10.1155/2012/195073

2. Crawford PM. Epidemiology of intractable epilepsy. In: Oxbury J, Polkey C, Duchowny M, editors. Intractable focal epilepsy. London: WB Saunders; 2000.

3. Hemb M, Palmini A, Paglioli E, Paglioli EB, Costa JC, Azambuja N et al. An 18-year follow-up of seizure outcome after surgery for temporal lobe epilepsy and hippocampal sclerosis. J Neurol Neurosurg Psychiatry. 2013;84(7):800-5. http://dx.doi.org/10.1136/ jnnp-2012-304038

4. Kieling RR, Palmini A, Paglioli E. Treatment of refractory mesial temporal lobe epilepsy. JAMA. 2012;307(23):2483. http://dx.doi.org/ 10.1001/jama.2012.4985

5. Engel J Jr, Van Ness PC, Rasmussen T, et al. Outcome with respect to epileptic seizures. In: Engel J, ed. Surgical treatment of the epilepsies. 2nd ed. New York: Raven; 1993. p. 609-21.

6. Paglioli E, Palmini A, Costa JC, Portuguez M, Martinez JV, Calcagnotto Me et al. Survival analysis of the surgical outcome of temporal lobe epilepsy due to hippocampal sclerosis. Epilepsia. 2004;45(11):1383-91. http://dx.doi.org/10.1111/j.0013-9580.2004.22204.x

7. Wiebe S, Blume W, Girvin J, Eliasziw M. A randomized, controlled trial of surgery for temporal-lobe epilepsy. N Engl J Med. 2001;345(5):311-8.

8. Yașargil MG, Teddy PJ, Roth P. Selective amygdalo-hippocampectomy. Operative anatomy and surgical technique. Adv Tech Stand Neurosurg. 1985;12:93-123.

9. Wieser HG, Yasargil MG. Selective amigdalohippocampectomy as a surgical treatment of mesiobasal limbic epilepsy. Surg Neurol. 1982;17(6):445-7.

10. Srikijvilaikul T, Lerdlum S, Tepmongkol S, Shuangshoti S. Outcomes after temporal lobectomy for temporal lobe epilepsy with hippocampal sclerosis. J Med Assoc Thai. 2012;95(9):1173-7.

11. Engel J, McDermott MP, Wiebe S, Langfitt JT, Stern JM, Dewar S et al. Early surgical therapy for drug-resistant temporal lobe epilepsy: a randomized trial. JAMA. 2012;307(9):922-30. http://dx.doi.org/10.1001/ jama.2012.220.

12. Kieling RR, Palmini A, Paglioli E. Treatment of refractory mesial temporal lobe epilepsy [letter]. JAMA. 2012;307(23):2483. http://dx. doi.org/10.1001/jama.2012.4985

13. Rhoton AL Jr. The cerebrum. Neurosurgery. 2007;61 (1 Suppl):SHC37-119. http://dx.doi.org/10.1227/01.NEU.0000255490.88321.CE
14. Olivier A. Transcortical selective amygdalohippocampectomy in temporal lobe epilepsy. Can J Neurol Sci. 2000;27Suppl 1:S68-76.

15. Spencer D, Burchiel K. Selective amygdalohippocampectomy. Epilepsy Res Treat 2012;2012:382095. http://dx.doi.org/10.1155/ 2012/382095

16. Wheatley BM. Selective amygdalohippocampectomy: the transmiddle temporal gyrus approach. Neurosurg Focus. 2008;25(3):E4. http://dx.doi.org/10.3171/FOC/2008/25/9/E4

17. Wen HT, Rhoton AL Jr, Oliveira E, Cardoso AC, Tedeschi H, Baccanelli $\mathrm{M}$ et al. Microsurgical anatomy of the temporal lobe: part 1: mesial temporal lobe anatomy and its vascular relationships as applied to amygdalohippocampectomy. Neurosurgery. 1999;45(3):549-91.

18. Wen HT, Rhoton AL Jr, de Oliveira E, Castro LH, Figueiredo EG, Teixeira MJ. Microsurgical anatomy of the temporal lobe: part 2sylvian fissure region and its clinical application. Neurosurgery 2009;65(Suppl 6):S1-S35.

19. Paglioli E, Palmini A, Portuguez M, Pagli E, Azambuja N, Costa JC et al. Seizure and memory outcome following temporal lobe surgery: selective compared with nonselective approaches for hippocampal sclerosis. J Neurosurg. 2006;104(1):70-8.

20. Niemeyer P. The transventricular amigdalohippocampectomy in temporal lobe epilepsy. In: Baldwin M, Bailey P, editors. Temporal lobe epilepsy. Springfield: Charles Thomas;1958. p. 461-82.

21. Thom M, Mathern GW, Cross JH, Bertram EH. Mesial temporal lobe epilepsy: How do we improve surgical outcome? Ann Neurol. 2010;68(4):424-34. http://dx.doi.org/ 10.1002/ana.22142

22. Palmini A. Epilepsy after epilepsy surgery. In: Shorvon SD, Anderman $F$, Guerrini R, editors. The causes of epilepsy, common and uncommon causes in adults and children. Cambridge: Cambridge University Press; 2011. p. 413-24.

23. Wen HT, Rhoton AL Jr, Marino R Jr. Gray matter overlying anterior basal temporal sulci as an intraoperative landmark for locating the temporal horn in amygdalohippocampectomies. Neurosurgery. 2006;59(4 Suppl 2):S221-7. 10.1227/01.NEU.0000223351.19962.D8

24. Campero A, Tróccoli G, Martins C, Fernandez-Miranda JC, Yasuda A, Rhoton AL Jr. Microsurgical approaches to the medial temporal region: an anatomical study. Neurosurgery. 2006;59(4 Suppl 2):S279-307. 10.1227/01.NEU.0000223509.21474.2E

25. Rubino PA, Rhoton AL Jr, Tong X, Oliveira E. Three-dimensional relationships of the optic radiation. Neurosurgery. 2005;57(4 Suppl):219-27. 10.1227/01.NEU.0000176415.83417.16 
26. Erdem A, Yașargil G, Roth P. Microsurgical anatomy of the hippocampal arteries. J Neurosurg 1993;79(2):256-65.

27. Wen HT, Rhoton AL Jr, Oliveira E, Castro LH, Figueiredo EG, Teixeira MJ. Microsurgical anatomy of the temporal lobe: part 2sylvian fissure region and its clinical application. Neurosurgery. 2009;65(6 Suppl):S1-35. 10.1227/01.NEU.0000336314.20759.85

28. Isolan GR, Azambuja N, Paglioli Neto E, Paglioli E. Anatomia microcirúrgica do hipocampo na amígdalo-hipocampectomia seletiva sob a perspectiva da técnica de Niemeyer e método préoperatório para maximizar a corticotomia. Arq Neuro-psiquiatr. 2007;65(4A):1062-9.

29. Yeni SN, Tanriover N, Uyanik O, Ulu MO, Ozkara C, Karaağaç N, Ozyurt E, Uzan M. Visual field defects in selective amygdalohippocampectomy for hippocampal sclerosis: the fate of Meyer's loop during the transsylvian approach to the temporal horn. Neurosurgery 2008;63:507-515. 